\title{
Cost and outcome of occupation-based practice for community dwelling frail elderly: a pilot study
}

This article was published in the following Dove Press journal:

Clinical Interventions in Aging

\author{
Hirofumi Nagayama' \\ Norikazu Kobayashi ${ }^{2}$ \\ Yu Ishibashi ${ }^{2}$ \\ Ryuji Kobayashi ${ }^{2}$ \\ Chika Murai ${ }^{3}$ \\ Keita Yamauchi ${ }^{4}$ \\ 'Department of Occupational \\ Therapy, Kanagawa University of \\ Human Services, Yokosuka, Japan; \\ ${ }^{2}$ Division of Occupational Therapy, \\ Faculty of Health Sciences, Tokyo \\ Metropolitan University, Arakawa, \\ Japan; ${ }^{3}$ Department of Occupational \\ Therapy, Ishikawa Prefectural \\ Takamatsu Hospital, Kahoku, \\ Japan; ${ }^{4}$ Graduate School of Health \\ Management, Keio University, \\ Fujisawa, Japan
}

Purpose: The purpose of this pilot study was to determine the effectiveness and costs of the occupation-based practice for community dwelling frail elderly.

Design: Pilot pre-post design without a control group.

Setting: A care management center involving 37 local elderly.

Subject: The final analysis included 26 frail elderly in a community dwelling center.

Intervention: The intervention was occupation-based practice involving setting of clientcentered goals, observation of real living situations, and provision of advice on the individual problem of real occupation.

Outcome: The outcome was the Frenchay Activities Index (FAI), which is used to evaluate the instrumental activities of daily living (IADL). Additionally, the frequency, duration, and cost of the intervention were calculated.

Results: Regarding the FAI score before and after the interventions, there were significant improvements in all items except work $(P<0.05$, effect size $[\mathrm{r}]: 0.67-0.93)$. A total of 15 people out of $26(57.7 \%)$ showed improvement in activities of daily living. The frequency of interventions was 3.7 (95\% confidence interval [CI]: 2.83-4.48), and the duration was 7.4 weeks $(95 \% \mathrm{CI}$ : 5.27-9.42). The average intervention cost was \$258 (95\% CI: 200.4-317.4).

Conclusion: The results of this study showed that occupation-based practice has a potential to improve IADL in frail elderly, with low frequency of intervention, within a short-term, and direct cost reduction. We believe that this pilot study will contribute to future clinical studies for frail elderly, and the findings can be easily applied to daily clinical intervention. A well-designed prospective randomized-controlled trial is necessary to verify these results.

Keywords: activities of daily living, Frenchay Activities Index, frail elderly, occupational therapy, cost saving

\section{Introduction}

Frailty is an important clinically identifiable state that increases the vulnerability to adverse outcomes, because of the decline in reserve and functionality of multiple physiological systems. ${ }^{1}$ The phenotype of frailty is defined as having three or more of the following criteria: unintentional weight loss, self-reported exhaustion, weakness, slow walking speed, and low physical activity. ${ }^{2}$ Frailty is a significant predictor of the incidence and worsening of activities of daily living (ADL) and poses limitations in instrumental activities of daily living (IADL) for community dwelling elderly; subsequently, this is associated with increased health care costs. ${ }^{3-5}$ Therefore, reducing the prevalence of frailty is likely to be greatly beneficial for the individual, their families, and society as a whole. ${ }^{3}$

A previous systematic review and meta-analysis showed that home- and communitybased occupational therapy had significant positive effects on daily living activities,
Correspondence: Hirofumi Nagayama Department of Occupational Therapy, Kanagawa University of Human Services, I-I0-I Heiseicho, Yokosuka,

Kanagawa 238-8522, Japan

Tel +81468282724

Fax +81468282725

Email hirofuminagayama@gmail.com (c) (1) (-) 2018 Nagayama et al. This work is published and licensed by Dove Medical Press Limited. The full terms of this license are available at https://www.dovepress.com/terms.php (c) ${ }_{\mathrm{BY}} \mathrm{NC}$ and incorporate the Creative Commons Attribution - Non Commercial (unported, v3.0) License (http://creativecommons.org/licenses/by-nc/3.0/). By accessing the work you hereby accept the Terms. Non-commercial uses of the work are permitted without any further permission from Dove Medical Press Limited, provided the work is properly attributed. For permission for commercial use of this work, please see paragraphs 4.2 and 5 of our Terms (https://www.dovepress.com/terms.php). 
social participation, and the mobility of frail elderly. ${ }^{6}$ However, in that review, there were variations in the frequency and duration of the interventions. Although an efficient preventive intervention may involve a short duration and low frequency, its effectiveness and the appropriate duration are unclear. ${ }^{7}$ Understanding these characteristics of the intervention is required.

Subsequently, we need to determine what type of occupational therapy is most effective in the short-term for community dwelling frail elderly. Occupation-based practice evaluation and interventions should be based on occupations, including purposeful and meaningful activities for the individual in a social context, rather than focusing on impairments or body structure. ${ }^{8,9}$ Evaluation and interventions involving meaningful activities might enhance autonomy and the sense of purpose in life, and it may help maintain or improve ADL in elderly. ${ }^{10}$ Occupation-based practice may significantly improve occupational performance in older, home-dwelling adults with physical health problems. ${ }^{11}$

Therefore, we have focused on occupation-based practice, because this intervention method focuses on daily activities, and reports have shown its short-term effectiveness in disabled elderly. ${ }^{11,12}$ We hypothesized that short-time and low-frequency occupation-based practice is effective in improving ADL and IADL for frail elderly. The purpose of this pilot study was to determine the effectiveness and costs of the occupation-based practice in community dwelling frail elderly, with regard to the number of interventions, intervention duration, and cost.

\section{Methods}

This was a pilot study with a pre-post design; assessments were made before and after an intervention, without a control group. This study was approved by the ethics committee of the Tokyo Metropolitan University (No 16062) and The Japanese Association of Occupational Therapists (No 201604). All participants provided informed written consent before the study.

\section{Participants}

The participants of this study were community dwelling frail elderly who received preventive services in 37 local elderly care management centers (recruitment period from October 2016 to February 2017). We defined frailty among the participants of this study as being under the cutoff point in the KIHON checklist (KCL) or being certified as requiring support by Long-Term Care Insurance (the KCL cutoff point is shown in Appendix 1). This is the standard definition for
Appendix I Cutoff point of KIHON checklist

\begin{tabular}{|c|c|}
\hline $\begin{array}{l}\text { KCL } \\
\text { question }\end{array}$ & Criterion to define frailty \\
\hline No I-20 & $\begin{array}{l}\text { Negative answer on more than } 10 \text { of } 20 \text { questions } \\
\text { (excluding } 5 \text { questions in the mood category) }\end{array}$ \\
\hline No $6-10$ & $\begin{array}{l}\text { Negative answer on } 3 \text { of } 5 \text { questions in the } \\
\text { physical strength category }\end{array}$ \\
\hline No $11-12$ & $\begin{array}{l}\text { Negative answer on all questions in the nutrition } \\
\text { category ( } 2 \text { questions) }\end{array}$ \\
\hline No $13-15$ & $\begin{array}{l}\text { Negative answer on } 2 \text { of } 3 \text { questions in the eating } \\
\text { category }\end{array}$ \\
\hline No $16-17$ & $\begin{array}{l}\text { Negative answer on question \#16 in the } \\
\text { socialization category }\end{array}$ \\
\hline No $18-20$ & $\begin{array}{l}\text { Negative answer on } 3 \text { of } 5 \text { questions in the } \\
\text { memory category }\end{array}$ \\
\hline No $21-25$ & $\begin{array}{l}\text { Negative answer on } 2 \text { of } 5 \text { questions in the mood } \\
\text { category }\end{array}$ \\
\hline
\end{tabular}

Abbreviation: $\mathrm{KCL}, \mathrm{KIHON}$ checklist.

receiving nursing care prevention services in Japan. ${ }^{13} \mathrm{KCL}$ is a self-reported comprehensive health checklist designed by a study group from the Japanese Ministry of Health, Labour and Welfare as a screening tool to identify community dwelling older adults who are vulnerable to frailty and having a higher risk of becoming dependent. ${ }^{13,14}$ The KCL comprises 25 items (yes/no) divided into seven categories: physical strength, nutrition, eating, socialization, memory, mood, and lifestyle; each category is rated on a pass (0)/fail (1) basis, and the sum of all indices ranges from 0 (no frailty) to 25 (severe frailty) where a higher score indicates worse functioning. ${ }^{13-15}$

Participants were included if they had been certified as having frailty according to the abovementioned criteria, were $\geq 65$ years old, had difficulty performing IADL, and were only receiving home services. The exclusion criteria were receiving home services as well as day-care or other services. Additionally, we excluded participants who were judged by a primary physician or occupational therapist as being unable to undergo rehabilitation intervention.

\section{Intervention}

The intervention in this study was occupation-based practice conducted by occupational therapists. Occupation-based practice evaluation and interventions should be based on real-life activities, rather than focusing on impairments or body structure. Typically, the therapists did not conduct direct therapeutic intervention (such as relaxation and manual therapy) for motor or body function, but rather provided the necessary advice with regards to the specified real-life occupation (doing meaningful activities in their real environment) for each participant. Intervention involved encouraging the 
subject to personally solve the problem within a short time. The procedure is described in the following text.

\section{Interview and client-centered goal setting}

The occupational therapists identified the real-life occupation through interviews conducted at the homes of the participants. Therapists informed the participants that no direct therapeutic interventions would be performed. Goal setting was done considering the following 4 viewpoints: 1) to include the name of daily activities, 2) to include the period necessary for goal setting, 3 ) to indicate one goal, and 4) to document in the words of the participants.

\section{Discussing the medical risks of participants with other professionals}

Therapists confirmed the medical risks of the participants with other professionals. When necessary, therapists also collaborated with other professionals to provide support in the daily activities of participants.

\section{Observation of real-life occupations at home}

The therapist observed real-life occupations at home and evaluated improvement in body/cognitive function and the possibility of changing the local environment and procedure.

\section{Advice for real-life occupations}

Based on the results from the observations, therapists provided advice on real-life occupations. Most importantly, participants were encouraged to solve their own problems. Some advice included the need 1) to adjust the difficulty level of daily activities; 2 ) to reconsider a habit; 3 ) to reconsider the tools; 4) to reconsider the roles; 5) to break down daily activities; 6) to change the environment; and 7) to use an assistive device.

\section{Outcome}

The outcome of this study was the Frenchay Activities Index (FAI), which is used for evaluating the IADL. ${ }^{16}$ The FAI evaluates each of the 15 items in IADL based on a score of $0-3$ points according to the frequency of activity for 3 months (45 points in total). We used the Japanese version of the FAI, which calculates the total score and sub-score of each of the following items: indoor housework, outdoor housework, outdoor activities, hobbies, and work area score. ${ }^{17,18}$ The FAI was scored by an occupational therapist before and after the intervention. We also calculated the frequency and duration of the intervention to examine its cost. The intervention cost was the same as the cost of home-based rehabilitation in long-term care insurance (20 $\mathrm{min} / 4000 \mathrm{JPY})$, which was converted to EUR and USD at the rate as of February 2017 (http://www.X-rates.com/).

\section{Statistical methods}

The total FAI scores were compared using paired $t$-test. Wilcoxon signed-rank test was used to determine whether there was a difference in sub-scores before and after the intervention. For all analyses, a $P$-value $<0.05$ was considered statistically significant. In addition, we calculated each effect size (r) and its 95\% confidence interval (CI). For analyzing the frequency of interventions, duration, and the intervention cost, we calculated the mean and 95\% CI. Data were processed using Stata 14.2 software.

\section{Results \\ Participants and baseline characteristics}

The final number of participants was 26 (Figure 1). The mean age of the participants was $76.7 \pm 7.84$ years of age, with the majority living together with a spouse (42.3\%) (Table 1). Among all conditions, orthopedic disorders were most common $(46.2 \%)$. With regards to "going out", once a week was the most frequent response $(76.9 \%)$ (Table 1).

\section{Outcome}

The FAI scores were significantly improved after the intervention for all items except work $(P<0.05)$ (Table 2). In total, ADL in 15 people (57.7\%) improved. The mean frequency of interventions was 3.7 (95\% CI: 2.83-4.48), and the mean duration was 7.4 weeks ( $95 \%$ CI: 5.27-9.42), corresponding to approximately one intervention per 2-week period. The average intervention cost was $€ 243$ (95\% CI: 188.2-297.7).

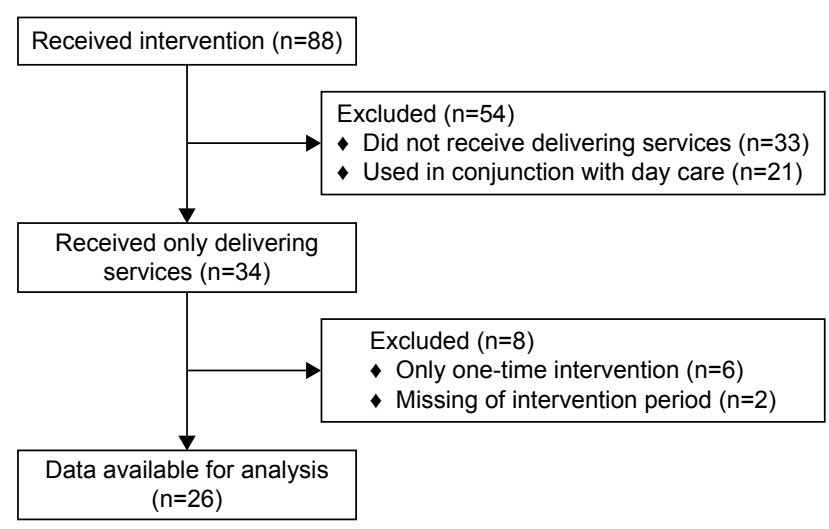

Figure I Flow diagram. 
Table I Baseline characteristics

\begin{tabular}{ll}
\hline & $\begin{array}{l}\text { Number (\%) } \\
\mathbf{n}=\mathbf{2 6}\end{array}$ \\
\hline Age [mean (SD)] & $76.7(7.84)$ \\
Gender (male) & $13(50.0 \%)$ \\
Cohabiter & \\
Solitude & $6(23.1 \%)$ \\
Husband-wife household & $11(42.3 \%)$ \\
More than 2 households & $9(34.6 \%)$ \\
Disease & \\
Orthopedic disease & $12(46.2 \%)$ \\
Stroke & $6(23.1 \%)$ \\
Diabetes & $2(7.7 \%)$ \\
Pneumonia & $2(7.7 \%)$ \\
Others & $4(15.4 \%)$ \\
Frequency of going out & \\
More than once/week & $20(76.9 \%)$ \\
More than once/month & $3(11.5 \%)$ \\
Almost without & $2(7.7 \%)$ \\
Unknown & $1(3.9 \%)$ \\
\hline
\end{tabular}

Abbreviation: SD, standard deviation.

\section{Discussion}

In this pilot study, the effectiveness and costs of occupationbased practice for frail elderly were investigated, based on a longitudinal comparison design without a control group. The results showed that occupation-based practice is effective in improving IADL in frail elderly, with low frequency and short-term intervention, suggesting the possibility of direct cost reduction. Although a few studies have examined the cost-effectiveness of other interventions, ${ }^{19}$ the intervention cost of this study was lower than that of previous interventions (intervention costs; $\$ 1,998^{20}$ or $\$ 859[€ 728]^{19}$ ). We believe that this pilot study contributes to future clinical studies for frail elderly, and our findings can be easily applied to daily clinical interventions.

We propose two reasons that low frequency, short-term occupation-based practice may have been effective. First, it involved client-centered goal setting; therefore, the client's problem-solving skills might be improved by participating in the goal setting, consequently motivating them to maintain their own health. Client-centered goal-setting and intervention processes ensure client empowerment and strengthen important aspects of effectiveness for frail elderly and their environment. ${ }^{6,21}$ Second, by evaluating real living situations, therapists were able to advise on individual problems regarding real occupations and thereby modify the real environment. By carefully analyzing ADL, the occupational therapist adapts skills or activities to the individual's demands, thus improving ADL performance. ${ }^{21}$

Several limitations of this study are acknowledged. First, the influence of possible confounding factors is undeniable since there was no control group. Therefore, it is necessary that prospective studies verify these results using a more appropriate randomized controlled trial (RCT) design. However, previous studies have reported that IADL declines in frail elderly, ${ }^{4}$ and the occupation-based practice of the present study resulted in a large effect size, suggesting that this intervention is likely to be effective. Second, owing to the small sample size, it is impossible to determine which participants were positively affected by the intervention. However, the

Table 2 Outcome measure

\begin{tabular}{|c|c|c|c|c|c|c|}
\hline & $\begin{array}{l}\text { Baseline } \\
\text { score } \\
\text { mean (SD) }\end{array}$ & $\begin{array}{l}\text { Post-score } \\
\text { mean (SD) }\end{array}$ & $\begin{array}{l}\text { Change in } \\
\text { score } \\
\text { mean }(95 \% \mathrm{CI})\end{array}$ & $\begin{array}{l}\text { Number of } \\
\text { changed scores } \\
\text { increase (\%) }\end{array}$ & $P$-value & $\begin{array}{l}\text { Effect } \\
\text { size }(r)\end{array}$ \\
\hline \multicolumn{7}{|l|}{ Frenchay Activities Index } \\
\hline Indoor housework & $7.0(5.67)$ & $8.2(5.50)$ & $1.2(0.34-2.03)$ & I I (42.3\%) & $0.004^{\mathrm{a}}$ & 0.93 \\
\hline Outdoor housework & $1.4(1.33)$ & $2.1(1.62)$ & $0.7(0.20-1.19)$ & $9(34.6 \%)$ & $0.003^{\mathrm{a}}$ & 0.67 \\
\hline Outdoor activities & $3.6(2.91)$ & $4.8(2.94)$ & I.2 (0.43-2.03) & 12 (46.2\%) & $0.00 \mathrm{I}^{\mathrm{a}}$ & 0.77 \\
\hline Hobby & $2.0(1.96)$ & $2.4(1.88)$ & $0.4(0.04-0.80)$ & $5(19.2 \%)$ & $0.026^{a}$ & 0.88 \\
\hline Work & $0.2(0.46)$ & $0.3(0.72)$ & $0.1(-0.06-0.29)$ & $2(7.7 \%)$ & $0.157^{a}$ & 0.82 \\
\hline Total & I5.I (9.15) & I 8.7 (8.50) & $3.7(1.525 .78)$ & 15 (57.7\%) & $0.002^{b}$ & 0.82 \\
\hline $\begin{array}{l}\text { Total number of } \\
\text { interventions (frequency) }\end{array}$ & 3.7 & $(2.83-4.48)$ & - & - & - & - \\
\hline \multicolumn{7}{|l|}{$\begin{array}{l}\text { interventions (frequency) } \\
\text { Mean }(95 \% \mathrm{Cl})\end{array}$} \\
\hline Intervention period (weeks) & 7.4 & $(5.27-9.42)$ & - & - & - & - \\
\hline \multicolumn{7}{|l|}{ Mean $(95 \% \mathrm{Cl})$} \\
\hline Intervention cost & JPY 29,23I & $(22,643.9-35,817.6)$ & - & - & - & - \\
\hline \multirow[t]{2}{*}{ Mean $(95 \% \mathrm{Cl})$} & EUR 243 & $(188.2-297.7)$ & & & & \\
\hline & USD 258 & $(200.4-317.4)$ & - & - & - & - \\
\hline
\end{tabular}

Notes: aWilcoxon signed-rank test; bpaired $t$-test.

Abbreviations: SD, standard deviation; $\mathrm{Cl}$, confidence interval. 
participants had a common characteristic, as frail elderly, and therefore the adaptation range of this intervention method did not seem limited. Third, we calculated only the intervention cost. In future, it is necessary to calculate the intervention costs as well as all care and medical costs to better analyze the cost-effectiveness alongside a control group.

\section{Conclusion}

In summary, the results of this study show that occupationbased practice, with low frequency and short-term intervention, is effective in improving IADL for frail elderly, suggesting the possibility of direct cost reduction. However, the influence of possible confounding factors on the results cannot be denied, because there was no control group. In the future, it is necessary to verify these results with a welldesigned RCT.

\section{Acknowledgment}

The authors would like to thank all the occupational therapists who participated in this study.

\section{Author contributions}

$\mathrm{HN}, \mathrm{NK}, \mathrm{RK}, \mathrm{YI}$, and CM conceived the study and designed the experiments. HK, NK, RK, YI, and CM performed the experiments. HN, NK, RK, and YI analyzed the data. HN, NK, RK, YI, and KY contributed reagents/materials/analysis tools. HN and KY drafted the manuscript. All Authors contributed toward data analysis, drafting and revising the paper and agree to be accountable for all aspects of the work.

\section{Disclosure}

The authors report no conflicts of interest in this work.

\section{References}

1. Walston J, Hadley EC, Ferrucci L, et al. Research agenda for frailty in older adults: toward a better understanding of physiology and etiology: summary from the American Geriatrics Society/National Institute on Aging Research Conference on Frailty in Older Adults. $J$ Am Geriatr Soc. 2006;54(6):991-1001.

2. Fried LP, Tangen CM, Walston J, et al; Cardiovascular Health Study Collaborative Research Group. Frailty in older adults: evidence for a phenotype. J Gerontol A Biol Sci Med Sci. 2001;56(3):M146-M156.

3. Clegg A, Young J, Iliffe S, Rikkert MO, Rockwood K. Frailty in elderly people. Lancet. 2013;381(9868):752-762.

4. Kojima G. Frailty as a predictor of disabilities among communitydwelling older people: a systematic review and meta-analysis. Disabil Rehabil. 2017;39(19):1897-1908.
5. Bock JO, Konig HH, Brenner H, et al. Associations of frailty with health care costs - results of the ESTHER cohort study. BMC Health Serv Res. 2016;16:128.

6. De Coninck L, Bekkering GE, Bouckaert L, Declercq A, Graff MJL, Aertgeerts B. Home- and community-based occupational therapy improves functioning in frail older people: a systematic review. $J \mathrm{Am}$ Geriatr Soc. 2017;65(8):1863-1869.

7. Ryburn B, Wells Y, Foreman P. Enabling independence: restorative approaches to home care provision for frail older adults. Health Soc Care Community. 2009;17(3):225-234.

8. Fisher AG. Occupation-centred, occupation-based, occupation-focused: same, same or different? Scand J Occup Ther. 2013;20(3):162-173.

9. Polatajko HJ, Davis JA. Advancing occupation-based practice: interpreting the rhetoric. Can J Occup Ther. 2012;79(5):259-262.

10. Nagayama $\mathrm{H}$, Tomori $\mathrm{K}$, Ohno $\mathrm{K}$, et al. Effectiveness and costeffectiveness of occupation-based occupational therapy using the aid for decision making in occupation choice (ADOC) for older residents: pilot cluster randomized controlled trial. PLoS One. 2016;11(3):e0150374.

11. Nielsen TL, Petersen KS, Nielsen CV, Strøm J, Ehlers MM, Bjerrum M. What are the short-term and long-term effects of occupation-focused and occupation-based occupational therapy in the home on older adults' occupational performance? A systematic review. Scand J Occup Ther. 2017;24(4):235-248.

12. Noto S, Murai C, Takeuchi S, Iwase Y, Nakamura H. Effect of occupational therapy using "the management tool for daily life performance" for dependent community-dwelling elderly: a randomized controlled multi-center trial. JPN Occup Ther. 2014;33(3):259-269.

13. Japanese Ministry of Health Law. The manuals of the evaluation for ability to perform daily activities on preventive care. Available from: http://www.mhlw.go.jp/topics/2009/05/d1/tp0501-1c_0001.pdf. Accessed March 10, 2018.

14. Nemoto M, Yabushita N, Kim MJ, Matsuo T, Seino S, Tanaka K. Assessment of vulnerable older adults' physical function according to the Japanese Long-Term Care Insurance (LTCI) system and Fried's criteria for frailty syndrome. Arch Gerontol Geriatr. 2012;55(2):385-391.

15. Fukutomi E, Okumiya K, Wada T, et al. Relationships between each category of 25-item frailty risk assessment (Kihon Checklist) and newly certified older adults under Long-Term Care Insurance: a 24-month follow-up study in a rural community in Japan. Geriatr Gerontol Int. 2015;15(7):864-871.

16. Holbrook M, Skilbeck CE. An activities index for use with stroke patients. Age Ageing. 1983;12(2):166-170.

17. Hachisuka K, Chisaka H, Kawazu T, Saeki S, Negayama S. Applied activities of daily living and its standard value determined according to Frenchay activities index scores for randomly sampled middle and advanced age people living at home. JPN J Rehabil Med. 2001;38(4): 287-295.

18. Suenaga H, Miyanaga K, Chisaka H, Kawazu T, Hachisuka K. Modified version of the self-rating Frenchay activities index and its reliability and validity. JPN J Occup Med Traumatol. 2000;48(1):55-60.

19. Metzelthin SF, van Rossum E, Hendriks MR, et al. Reducing disability in community-dwelling frail older people: cost-effectiveness study alongside a cluster randomised controlled trial. Age Ageing. 2015;44(3): 390-396.

20. Gill TM, Baker DI, Gottschalk M, Peduzzi PN, Allore H, Byers A. A program to prevent functional decline in physically frail, elderly persons who live at home. N Engl J Med. 2002;347(14):1068-1074.

21. Steultjens EM, Dekker J, Bouter LM, Jellema S, Bakker EB, van den Ende $\mathrm{CH}$. Occupational therapy for community dwelling elderly people: a systematic review. Age Ageing. 2004;33(5):453-460. 


\section{Publish your work in this journal}

Clinical Interventions in Aging is an international, peer-reviewed journal focusing on evidence-based reports on the value or lack thereof of treatments intended to prevent or delay the onset of maladaptive correlates of aging in human beings. This journal is indexed on PubMed Central, MedLine,

CAS, Scopus and the Elsevier Bibliographic databases. The manuscript management system is completely online and includes a very quick and fair peer-review system, which is all easy to use. Visit http://www.dovepress. com/testimonials.php to read real quotes from published authors. 